\title{
ANAEMIA AS AN AETIOLOGICAL FACTOR IN CONVERGENCE INSUFFICIENCY*
}

\author{
BY \\ N. MANSON \\ Department of Ophthalmology, Royal Victoria Infirmary, Newcastle upon Tyne
}

IN the year 1961-1962, 74 cases of convergence insufficiency were seen in the Ophthalmological Department of the Royal Victoria Infirmary (Table). It was interesting to note that the onset of symptoms amongst some of the female patients was related to incidents of anaemia. The anaemia was attributable in every case, either to a gynaecological or obstetric cause, or to the onset of physiological menstruation. Thus all the cases in which anaemia and convergence insufficiency co-existed occurred in females in the age group 10 to 45 years.

TABLE

ANALYSIS OF 74 CASES SEEN IN 1961-62

\begin{tabular}{c|c|c|c}
\hline Sex & No. of Cases & $\begin{array}{c}\text { No. Aged } \\
10-45 \text { yrs }\end{array}$ & $\begin{array}{c}\text { No. in This Age Group } \\
\text { with Anaemia }\end{array}$ \\
\hline Male & 29 & 20 & 0 \\
Female & 45 & 35 & 10 \\
\hline
\end{tabular}

It is not unlikely that anaemia can be casually related to convergence insufficiency in view of the prevalence of various degrees of hypochromic anaemia in women of this age group. It is of interest, however, to note the onset of symptoms as a definite sequel to a haemorrhage or menstrual pathology causing anaemia. Such conditions must provide additional cause for a latent muscular imbalance to become manifest or for insufficiency to appear where no imbalance previously existed. The association of an organic debility with inadequate convergence has long been recognized and the need to correct such debility is as important in improving the convergence insufficiency as are muscular exercises. The distribution of the cases by age and sex is shown in Fig. 1 (opposite), and the proportion of anaemic cases by sex in Fig. 2 (opposite).

The anaemic cases, occurring as they do in the female group only, are statistically significant. The age distribution between the sexes in the age group 10 to 45 years has no statistical significance. However, a likely explanation of the excess of female cases under 45 years is the existence of the ten anaemic cases. 

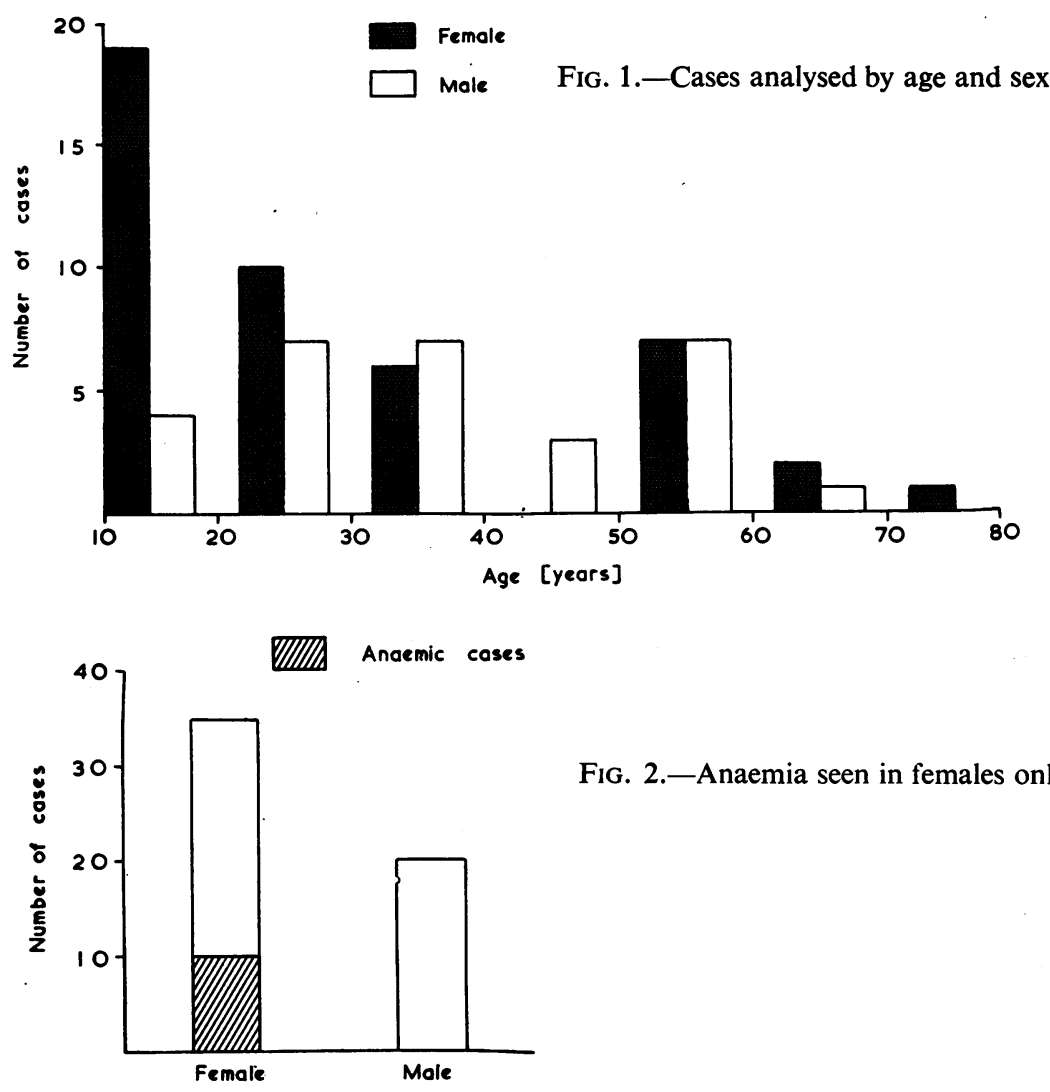

Fig. 2.-Anaemia seen in females only.

\section{Case Reports of Females aged 10 to 45 years}

Case 1, a woman aged 33 years, complained one month after a massive post partum haemorrhage in August, 1961, of difficulty with close work, anxiety in traffic and inability to judge distances.

\section{Examination}

REFRACTION:

Visual ACUITY:

PUPILS:

COVER TEST (near):

Livingston BinOcUlaR

GAUGE (cm.):

ACCOMMODATION

CONVERGENCE

SYNOPTOPHORE:
Before Treatment

Emmetropic

$$
6 / 6
$$

Sluggish reaction

Latent divergence with good recovery

Right 19

Left 18

Binocular 16

Subjective 18

Objective 15

Full binocular vision

Adduction $+20^{\circ}$

Abduction - $2^{\circ}$

\section{After Treatment}

$6 / 6$

Brisk reactions

No divergence

15

15

15

12

Full binocular vision

$+40^{\circ}$

$-5^{\circ}$ 
Laboratory Investigations.-Haemoglobin below 50 per cent. after the post partum haemorrhage, now 90 per cent.

Final State.-No symptoms.

Case 2, a woman aged 34 years, complained in 1955 of headache and discomfort after close work, of 6 months' duration, following the birth of her first baby; at this time she had an attack of rubella and was anaemic.

In May, 1958, she was again anaemic; the previous symptoms recurred and she attended for treatment in January, 1959.

In June, 1961, she was again anaemic and the symptoms returned.

Examination

REFRACTION:

Visual Acuity:

1955 Cover Test:

Binocular Convergence:

MADDOX WING:

SYNOPTOPHORE:

1959 SYNOPTOPHORE:

1961 SYNOPTOPHORE:
Before Treatment

Right +0.5 D sph.

Left +0.75 D sph.

$$
6 / 5
$$

Latent divergence with rapid recovery

to $4^{\prime \prime}$

Exo $10^{\circ}$

Adduction $+15^{\circ}$

Abduction - $4^{\circ}$

Adduction $+20^{\circ}$

Abduction - $4^{\circ}$

Adduction $+30^{\circ}$

Abduction - $4^{\circ}$
After Treatment

No divergence

to $2^{\prime \prime}$

$0^{\circ}$

$+50^{\circ}$

$-5^{\circ}$

$+50^{\circ}$

$-5^{\circ}$

$+48^{\circ}$

$-5^{\circ}$

Laboratory Investigation.- Haemoglobin estimations varied from 50 per cent. after parturition to 85 per cent. after treatment.

Case 3, a woman aged 33 years, experienced frontal and occipital headaches and aching eyes when doing close work after the birth of her last child in October, 1961. She received irregular courses of oral iron for menorrhagia and anaemia.

\section{Examination}

REFRACTION:

VISUAL ACUITY:

Cover Test (near):

Binocular CONVERgence:

Prism Convergence:

MADDOX WING:

SYNOPTOPHORE:
Before Treatment

Emmetropic

$6 / 6$

Latent divergence with good recovery

to $1^{\prime \prime}$

$35 \Delta$ near vision

Orthophoric

Adduction $+25^{\circ}$

Abduction - $5^{\circ}$
After Treatment

Emmetropic

$6 / 6$

No divergence

to $1^{\prime \prime}$

$40 \triangle$ near vision

Orthophoric

$+40^{\circ}$

$-5^{\circ}$

Laboratory Investigations.-Present haemoglobin 75 per cent.

Final State.-Occasional symptoms.

Case 4, a woman aged 22 years, experienced headaches and diplopia for one year following parturition. She was anaemic at this time. While she was attending the Eye Department for the convergence insufficiency, she was also receiving treatment by her home doctor for her anaemia, and it was found after the second orthoptic treatment that the convergence had become normal. 
Examination

REFRACTION:

VisuAl ACUITY:

COVER Test (near):

(distance):

BinOCULAR CONVERGENCE:

MADDOX WING:

SYNOPTOPHORE:
Before Treatment

Emmetropic

$6 / 5$

Latent divergence with good recovery

No deviation

$2^{\prime \prime}$ poorly maintained

Exo. $2^{\circ}$

Simultaneous macular perception

Fusion $0^{\circ}$

Adduction $+20^{\circ}$

Abduction $-5^{\circ}$
After Treatment

Emmetropic

$6 / 5$

Latent divergence with good recovery

No deviation

$1^{\prime \prime}$ well maintained

Exo. $2^{\circ}$

Case 5, a girl aged 13 years, complained of fatigue, frontal headaches and blurring of vision for close work, 4 months after starting menstruation at the age of 12 years.

\begin{tabular}{|c|c|c|}
\hline Examination & Before Treatment & After Treatment \\
\hline REFRACTION: & Both Eyes: + 0.25 D. sph. & Same \\
\hline Visual ACUITY: & $6 / 6$ & $6 / 6$ \\
\hline $\begin{array}{r}\text { Cover TEST (near): } \\
\text { (distance) }\end{array}$ & $\begin{array}{l}\text { Latent divergence with good } \\
\text { recovery } \\
\text { No deviation }\end{array}$ & $\begin{array}{l}\text { No deviation } \\
\text { No deviation }\end{array}$ \\
\hline BINOCULAR CONVERGENCE: & $1^{\prime \prime}$ poorly maintained & $1^{\prime \prime}$ well maintained \\
\hline MaDDOX WING & Orthophoric & Orthophoric \\
\hline SYNOPTOPHORE: & $\begin{array}{l}\text { Simultaneous macular perception } \\
\qquad+4^{\circ} \\
\text { Fusion } 0^{\circ} \\
\text { Adduction }+10^{\circ} \\
\text { Abduction }-5^{\circ}\end{array}$ & $\begin{array}{r}+2^{\circ} \\
0^{\circ} \\
+50^{\circ} \\
-\quad 5^{\circ}\end{array}$ \\
\hline
\end{tabular}

Final State.-No symptoms. Present haemoglobin 75 per cent.

Since these cases were seen, two other women with convergence insufficiency have been examined, and the correction of the anaemia resulted in resolution of the ocular symptoms and return to normal of the orthoptic measurements, without orthoptic exercises.

\section{Summary}

74 cases of convergence insufficiency were examined in relation to hypochromic anaemia. The age and sex distribution and occurrence of anaemia are analysed. Anaemia occurred in a significant number of females aged 10 to 45 years.

Where convergence insufficiency appears in younger women, anaemia would seem to bear more than a casual relationship to a latent muscular imbalance, or to be a cause per se where no previous imbalance existed.

I should like to thank Mr. H. Vernon Ingram and Mr. L. H. Lake for allowing me to comment on these cases and the Misses M. F. Brown and J. F. Maughan for their observations. 